Recepción: 22 / 05 / 2018

Aceptación: 14 / 07 / 2018

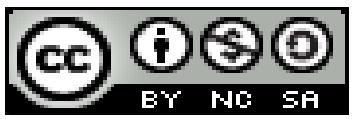

Ciencias económicas y empresariales

Publicación: 15 / 09 / 2018

Artículo de investigación

\title{
Tendencias de la pobreza y la desigualdad en el Ecuador y América latina
}

\section{Trends in poverty and inequality in Ecuador and latin America}

\section{Tendências da pobreza e da desigualdade no Equador e na América latina}

\author{
Marina Mero-Figueroa ${ }^{\mathrm{I}}$ \\ marina.merof@ug.edu.ec \\ Ángel C. Alvarado-Gastiaburo II \\ angel.alvaradog@ug.edu.ec
}

\section{Correspondencia: marina.merof@ug.edu.ec}

I Economista, Máster Latinoamericano en Evaluación de Políticas Públicas. Decana de la Facultad de Ciencias Económicas de la Universidad de Guayaquil, Guayaquil, Ecuador.

II Economista, Abogado, Master en Negocios Internacionales y Gestión de Comercio Exterior, Coordinador de Posgrado de la Facultad de Ciencias Económicas de la Universidad de Guayaquil, Guayaquil, Ecuador. 


\title{
Resumen
}

El objetivo del presente artículo es presentar las tendencias mostradas por el Ecuador y los demás países de América Latina en cuanto a la evolución de la pobreza y la desigualdad distributiva. Con este fin se utiliza información de las bases de datos de instituciones como CEPAL, INEC, Ministerio de Finanzas y SENPLADES, a través de los cuáles se muestran tablas y gráficos que nos dan una perspectiva de esta problemática que persiste en la región, aunque se han logrado avances en el combate a la pobreza y en la reducción de las desigualdades, estas se mantienen como características inherentes de las economías subdesarrollados.

Palabras claves: pobreza; desigualdad; Ecuador; gasto público.

\begin{abstract}
The objective of this article is to present the trends shown by Ecuador and the other countries of Latin America in terms of the evolution of poverty and distributive inequality. To this end, information is used from the databases of institutions such as ECLAC, INEC, Ministry of Finance and SENPLADES, through which tables and graphs are presented that give us a perspective of this problem that persists in the region, although they have made progress in combating poverty and in reducing inequalities, these remain inherent characteristics of underdeveloped economies.
\end{abstract}

Keywords: poverty; inequality; Ecuador; public spending.

\section{Resumo}

O objetivo deste artigo é apresentar as tendências apresentadas pelo Equador e outros países da América Latina em termos da evolução da pobreza e da desigualdade distributiva. Para tanto, utiliza-se informação das bases de dados de instituições como CEPAL, INEC, Ministério da Fazenda e SENPLADES, através das quais são apresentados tabelas e gráficos que nos dão uma perspectiva desse problema que persiste na região, embora eles progrediram no combate à pobreza e na redução das desigualdades, permanecem características inerentes às economias subdesenvolvidas.

Palavras chave: pobreza; desigualdade; Equador; gastos públicos. 


\section{Introducción}

Con la frase célebre donde hay justicia no hay pobreza comienza este artículo. Una frase que desde la época en la que fue pronunciada y gravada continúa hasta hoy como si se hubiera pronunciado ayer y en nuestro continente. La lucha por la justicia, específicamente una retribución justa del trabajo y la riqueza, es lo que conlleva a una disminución de la pobreza no solo se da en Latinoamérica, es algo que se vive en todo el mundo. Sin embargo, la pobreza en Latinoamérica tiene una característica especial, la mala distribución de la riqueza, pues no somos un continente pobre, y sin recursos de subsistencia.

La pobreza se la puede entender como una condición socioeconómica en la que se encuentra un individuo u hogar, de modo que los recursos monetarios que posee no le permiten satisfacer sus necesidades básicas.

La realidad es que la pobreza persiste como un fenómeno estructural en Latinoamérica. En la última década los países latinoamericanos muestran avances significativos en la disminución de la pobreza, comparada con la década de los 90. Las cifras actualizadas de la pobreza en América Latina, reflejan un contexto de desaceleración de la economía regional desde el año 2010; la tasa de pobreza por ingresos se ha estancado desde el 2011 y desde el 2012 hasta el 2014 no se han logrado cambios significativos.

La comisión Económica para América Latina y El Caribe (CEPAL) a lo largo de la historia ha desarrollado distintas investigaciones sobre la pobreza. En su informe Panorama Social 2014, la analiza desde dos ámbitos: por ingresos, y desde una perspectiva multidimensional. Por lo tanto, en cuanto a la intensidad de la pobreza (porcentaje de privaciones que experimentan los hogares pobres), esta se redujo en el período antes mencionado. Respecto al índice multidimensional de pobreza (compuesto de aspectos monetarios y no monetarios del bienestar), este presenta un avance con respecto al año 2013. Los resultados muestran una caída de la incidencia de la pobreza multidimensional entre los años 2005-2012. En cuanto a la intensidad de la pobreza (porcentaje de privaciones que experimentan los hogares pobres), se redujo en el período antes mencionado.

Según el informe, en la última década se redujo la desigualdad en materia de distribución del ingreso, aunque este tema sigue siendo uno de los principales retos de la región. Las últimas 
estadísticas disponibles para 18 países indican que en promedio el 10\% más rico de la población latinoamericana recibe $32 \%$ de los ingresos totales, mientras que el $40 \%$ más pobre recibe solo $15 \%$.

Por otra parte, la CEPAL (2012) advierte un cambio en la tendencia del gasto público social en la región. Hasta el año 2010 este seguía al alza en América Latina, tanto en montos absolutos como en proporción al gasto público total y al producto interno bruto (PIB) con respecto a las décadas anteriores, mostrando un carácter contra cíclico durante la crisis internacional. Sin embargo, datos parciales desde el 2011 indican que habría una tendencia a la contracción relativa del gasto social para robustecer las finanzas públicas, lo cual no significa necesariamente una reducción de los montos absolutos destinados a los sectores sociales.

Como ya se ha mencionado, una de las variables decisivas que incide en el nivel de pobreza de los países Latinoamericanos es la desigual distribución de la riqueza al interior de las naciones. Esta desigual distribución se puede corregir de algunas formas, a través de las diferentes políticas públicas hacia los sectores prioritarios, que se derivan o se muestran en la partida del gasto público destinado comúnmente a incentivar el sector social de la economía, o equilibrar de alguna forma esta torcida balanza.

Tal vez la forma más habitual de representar la desigualdad que tenemos los economistas es a partir de la famosa Curva de Lorenz. Esta medida fue propuesta en 1905 con el propósito de ilustrar la desigualdad en la distribución de la salud y, desde su aparición, su uso se ha popularizado entre los estudiosos de la desigualdad económica.

Sin embargo, en la práctica el indicador que ha tenido mayor aceptación en los trabajos empíricos es el denominado coeficiente de concentración de Gini. El coeficiente de Gini es una medida de desigualdad que se deriva a partir de la Curva de Lorenz. Este índice de fácil interpretación, es una referencia común en los debates sobre el bienestar y la equidad de los países de la región.

Comúnmente el índice de Gini se lo utiliza para medir la desigualdad en los ingresos dentro de un país o una subdivisión de este, pero puede utilizarse para medir cualquier forma de distribución desigual. El coeficiente de Gini es un número continuo que se presenta con una base de 0 y un máximo de 1; en donde el valor cero corresponde a una distribución con una perfecta igualdad, es decir todos tendrían los mismos niveles de renta, y el valor de uno correspondería a una perfecta 
desigualdad, monocentrismo del ingreso. Este será nuestro referente para analizar y comparar la pobreza en este libro.

En este trabajo mostramos un análisis de la evolución de la pobreza en el Ecuador y en el continente Latinoamericano. Describimos las características de la pobreza y su historia para el Ecuador, y detallamos algunas medidas que podría solucionar desde la perspectiva de la teoría y política económica a la sociedad ecuatoriana.

\section{Concentración de la riqueza: el panorama latinoamericano}

La CEPAL (2012) señaló que en el 2011 los ingresos del 20\% más rico de la población en Latinoamérica y el Caribe era 17 veces mayor que el del $20 \%$ más pobre, e inclusive se mencionó que esta diferencia podría llegar a hasta 25 veces mayor en países que presentaban una mayor desigualdad. En el 2012, en promedio, el quintil más pobre sólo obtuvo el 5\% de los ingresos totales del país con extremos que van desde menos de $4 \%$ en países como Bolivia, Honduras, Paraguay, República Dominicana, y con apenas un 10\% en Uruguay.

Además, tenemos la participación del quintil más rico, que se promediaba alrededor de un $47 \%$, con un rango que iría desde 35\% en Uruguay hasta un 55\% en Brasil. Como fue mencionado en el informe de la OXFAM (2014) de cada 100 dólares de ingresos que reciben los países en Latinoamérica y el Caribe, 5 llegan a los más pobres, cerca de 50 a los más ricos. Podemos también decir que en este informe se constató que la participación del quintil más pobre se incrementó en 11 de los 15 países en el período mencionado, habiéndose registrado aumentos de un punto porcentual o superiores en Argentina y Uruguay. La participación del quintil más rico se redujo en 11 de los 15 países considerados, registrándose caídas superiores al 4\% en Argentina, el Brasil y Uruguay. Adicionalmente, podemos mencionar que entre el 2008 y el 2013 en Costa Rica, Panamá y Paraguay hubo un descenso simultáneo de la participación en el ingreso del quintil más pobre y un aumento de la participación del quintil más rico de la población. 
Gráfico 1. Variación porcentual de los índices de desigualdad 2002-2008; 2008-2013 para América Latina (15 países) en porcentajes.

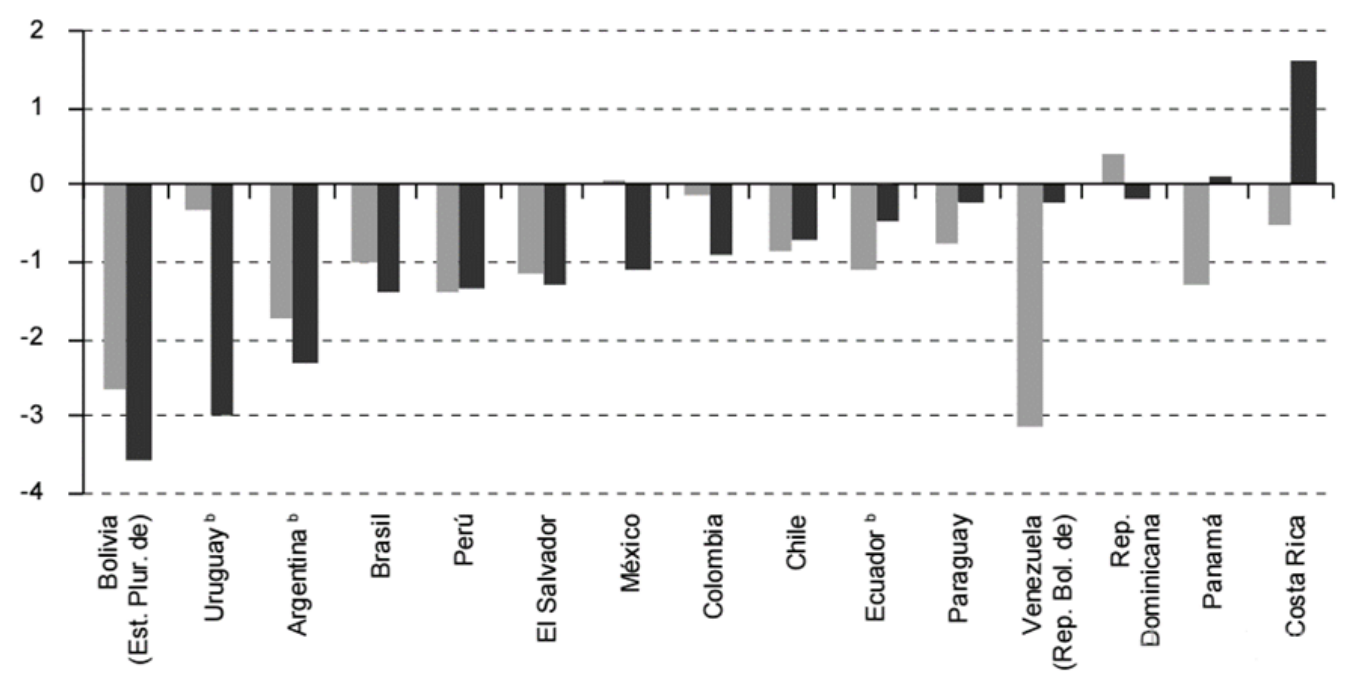

Tomado de: Comisión Económica para América Latina y el Caribe (CEPAL), Panorama Social de América Latina, pág. 100, 2014.

La dinámica de la reducción de la desigualdad muestra patrones diversos cuando se analiza el subperíodo de 2008 al 2013 en comparación con el comprendido entre 2002-2008.

Una de las causas de la pobreza en los países es la gran concentración de la riqueza en pocas manos, la mayoría de los países no son pobres en especial los latinoamericanos. En el continente existe riqueza, tanto natural como intelectual. Sin embargo, a la hora de hablar sobre los factores que inciden en una forma directa en la desigualdad de ingresos y de la distribución de la riqueza en el continente, podemos decir que están intrínsecamente unidos a nuestra idiosincrasia, que en muchos casos se mantienen desde la época colonial.

El color de nuestra piel, al ser un país y región con tanta variedad, donde se impone la blanca sobre las otras, siendo la negra e indígena la última de la sociedad en ser valorada. Si se es hombre o mujer, el lugar donde este nació, donde creció y estudió. Si viene del campo o la ciudad, si vive en la periferia o en el centro o norte, o simplemente si este es rico por herencia, entre muchos otros, nos llevan a cuestionarnos el caso de la discriminación, y como evitar y mejorar nuestros derechos en esta sociedad plurinacional. 


\section{La pobreza e indigencia en América Latina}

La pobreza e indigencia en AL disminuyeron a nivel regional, las tasas actuales son las más bajas de los tres últimos decenios. Situación que también se verifica en el Ecuador, dado que hay que tener en cuenta que el perfil de las personas pobres es, en varios aspectos, similar en los países latinoamericanos. La pobreza es un problema de tipo estructural que tiene características semejantes en todos los países de la región.

La tasa de pobreza e indigencia disminuyeron debido al incremento de la renta entre los pobres, es decir por un aumento en los ingresos laborales. El empleo remunerado ha sido una de las principales vías para salir de la pobreza. Además, los cambios en los aspectos demográficos, en los mercados de trabajo, en el contexto económico en general y en las respuestas institucionales a la pobreza, pudieron haber provocado una modificación paulatina en las características y perfiles de las personas carentes de recursos.

Este es un extraordinario proceso de transformación social, porque podemos decir que AL es una región de ingresos medios, en vías de convertirse en una región de clase media (Según los umbrales establecidos por el BM, una familia de cuatro personas se clasificaría como perteneciente a la clase media si sus ingresos ( 10 a $50 \$$ al día) anuales oscilaran entre 14.600 y 73.000 dólares).

Además, un 30,5\% de la población que vive en la pobreza (US\$0- US\$4 al día) y un 37,5\% que vive entre la pobreza y la clase media (US\$4-US\$10 al día). Este segundo grupo es un segmento de población corre el riesgo de caer en la pobreza. Dos factores - ingresos más altos y menos desigualdad de los ingresos - contribuyeron a la reducción de la pobreza y a la expansión de la clase media.

La última década está marcada por un crecimiento sostenido y por la disminución de la desigualdad en América Latina. La pobreza disminuyó del 40\% (2000) al 30\% en el 2010, lo que significó que unos 50 millones de habitantes salieron de la pobreza en este decenio. Aunque la mayoría de pobres que salieron de la pobreza no se integraron directamente en la clase media. Pasaron a un grupo situado entre los pobres y la clase media, la "clase de los vulnerables", actualmente constituye la clase más numerosa de la región. 
La clase media en AL creció de 100 millones de personas en 2000 a unos 150 millones en 2010. Las personas que pasan a formar parte de la clase media tienen un nivel educativo superior al de los pobres, y es más probable que vivan en zonas urbanas y tengan un empleo en el sector formal. En el caso de las mujeres de la clase media, es probable que tengan menos hijos y que estén más integradas a la fuerza laboral que las mujeres de los grupos pobres o vulnerables.

En un sentido más profundo, el auge de la clase media en la región también refleja una considerable movilidad económica ascendente. Concretamente, el movimiento hacia la clase media era mucho más probable entre las personas con algún nivel de educación terciaria. Asimismo, tener un empleo en el sector formal y vivir en una zona urbana también se constituye como factores que propician una movilidad ascendente.

La migración desde las zonas rurales a las zonas urbanas también se asociaba con mayores perspectivas de un movimiento ascendente, y esta asociación es más fuerte en los movimientos de la pobreza a la vulnerabilidad que en la transición hacia la clase media. En los países de América Latina y el Caribe se dio una clara relación entre el crecimiento acelerado del PIB y la mayor movilidad de los ingresos, que definen al crecimiento económico como el principal impulsor de la expansión de la clase media. Se observa que sí hubo una relación entre la movilidad y las medidas específicas de los programas de protección social progresivos, entre ellos, las transferencias condicionadas de efectivo, y el gasto en salud pública y educación.

El PIB per cápita creció una tasa anual de 2,2\% entre 2000 y 2010, que representa una mejora sustancial comparadas con el $0,2 \%$ negativo en los años 80 y un $1,2 \%$ positivo en los años noventa. Además, se observó una disminución de las disparidades de los ingresos. En todos los países de América Latina, los cabezas de familia de clase media tienen más años de escolarización que los de las clases pobres o vulnerables, pero menos años que los ricos. Los hogares de clase media también tienen más tendencia a vivir en zonas urbanas que los grupos más pobres.

Además, el empleo formal parece ser un signo distintivo de la clase media en América Latina: es más probable que el trabajador de clase media sea un empleado formal que un auto empleado, un desempleado o un empleador. Al contrario, los pobres y vulnerables dependen del autoempleo (o sufren el desempleo) más a menudo, mientras que los ricos son más frecuentemente empleadores. 
Si bien la AL ha emprendido el camino para convertirse en una región de clase media, aún queda mucho por hacer. Los líderes regionales tendrán que seguir dedicando una atención especial en materia de políticas a esa tercera parte de latinoamericanos que siguen siendo pobres, y a la vez, trabajar en aras de la seguridad y prosperidad de los vulnerables.

"Las actuales tasas de pobreza e indigencia son las más bajas observadas en las últimas tres décadas, pero aún estamos frente a niveles inaceptables en muchos países. El desafío es generar empleos de calidad en el marco de un modelo de desarrollo orientado a la igualdad y la sostenibilidad ambiental" CEPAL (2014).

Gráfico 2. América Latina: Evolución de la Pobreza y la Indigencia, 1980 -2014

(En porcentajes y millones de personas)
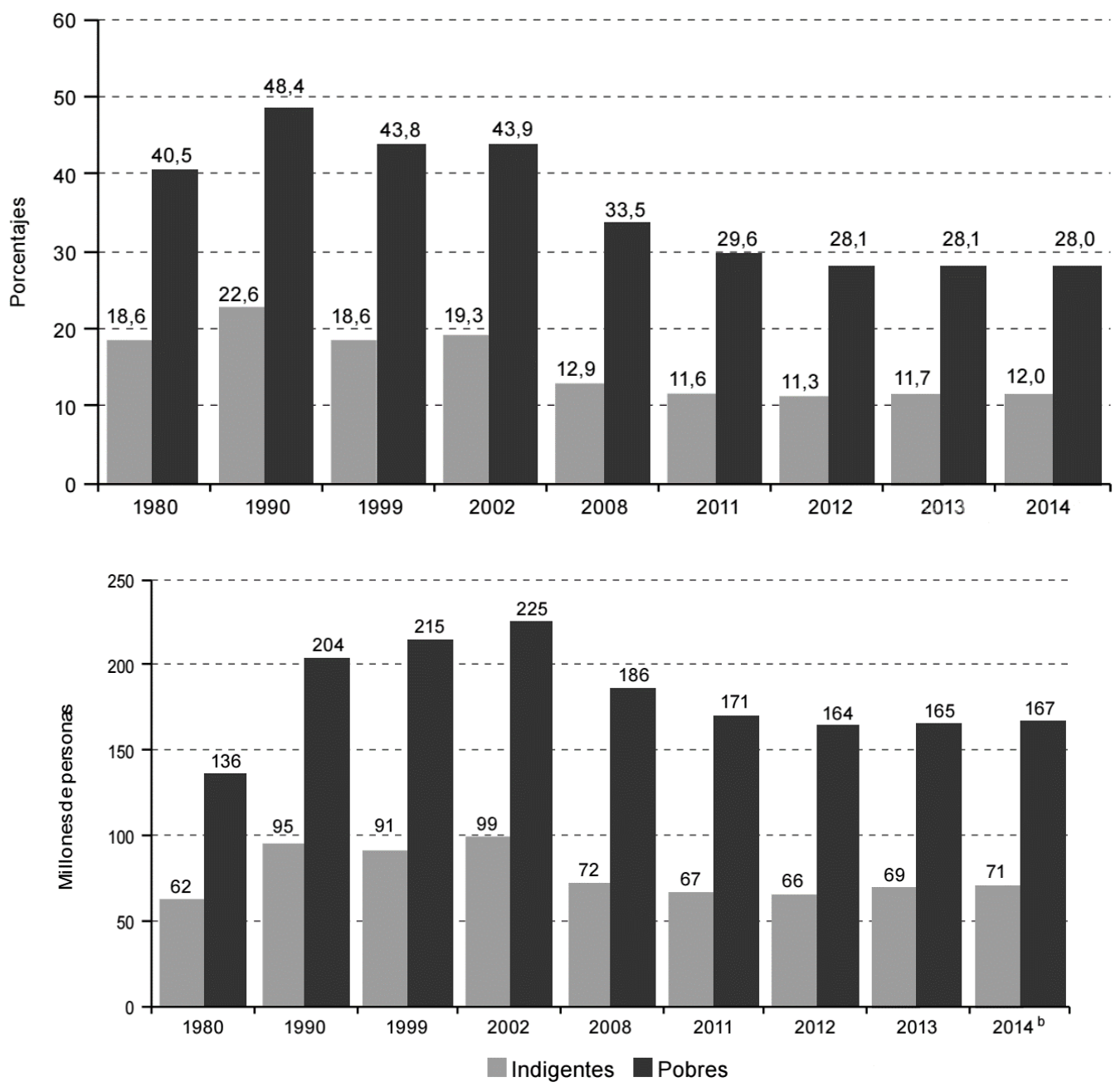

Fuente: Comisión Económica para América Latina y el Caribe (CEPAL), Panorama Social de América Latina, pág. 64, 2014. 
A partir del año 2011 hasta el 2014, las tendencias de reducción de la pobreza se han estancado, la tasa de pobreza en este período se ha mantenido en un $28 \%$, y respecto a la pobreza extrema, ésta alcanzó un 11,6\% a 12\% en el mismo período. Es decir, los valores dan cuenta que los porcentajes de pobreza y pobreza extrema se mantienen sin cambios significativos con respectos a los observados en el $2008(33,5 \% ; 12,9 \%)$ y el $2011(29,6 ; 11,6)$ respectivamente. Lo que muestra que la tendencia a la baja de las tasas de pobreza y pobreza extrema se ha desacelerado.

Hace unas décadas los pobres constituían el segmento más amplio de la población latinoamericana, esta disminución de la pobreza es el resultado de una transformación social, que se refleja en un crecimiento económico sostenido. Hay que tener en cuenta que la capacidad de un país para mejorar el nivel de vida de su población depende fundamentalmente de su tasa de crecimiento económico a largo plazo. En un largo período de tiempo, incluso una diferencia aparentemente pequeña entre las tasas de crecimiento económico puede traducirse en una gran diferencia en los niveles de renta de las personas.

Una variación de la tasa de crecimiento económico puede producir importantes efectos incluso en una o dos décadas. Esto es lo que ha ocurrido con América Latina y también en el caso particular de Ecuador. En el Ecuador en el año 2002, el 49,9\% de población era pobre, para el 2013 la tasa de pobreza disminuye al 33,6\% y la indigencia disminuyó del 19,4 al 12\%. Es decir, que la pobreza se redujo en apenas 11 años en 17 puntos porcentuales y la tasa de indigencia se redujo en 7 puntos porcentuales. Esta disminución importante en ambas tasas ubica al Ecuador como uno de los países de menor desigualdad de la región, cuando en 1999 era el tercer país más desigual, de acuerdo al resultado que se refleja en el coeficiente de Gini. Los cambios acumulados, dan cuenta de una evidente reducción de la desigualdad pasando del 0,526 en 1999 al 0,468 en 2013, medido por el coeficiente de Gini.

Si se analiza la evolución de la pobreza y la indigencia desde el año 1990 hasta el 2014, los resultados muestran una disminución significativa en la historia del Ecuador. En 1990 eran 204 millones de pobres, lo que equivalía al 48,4\% de los habitantes. La CEPAL (2012a) proyecta que la región finalizará el año 2014 con 167 millones de personas en situación de pobreza, lo que equivale a $28,8 \%$ de los habitantes. El número de personas en extrema pobreza o indigencia llega a 71 millones, 20 puntos porcentuales es una disminución significativa. 
Sin embargo, las tasas de pobrezas más bajas las tienen países como Argentina (4,3\%) en 2012, Chile (7,8 \%), Uruguay $(5,7 \%)$ y Costa Rica $(17,7 \%)$ en el año 2013, comparadas con la tasa de pobreza del Ecuador que llega al 33,6\%.

\section{Analizando su estructura este cambio en el nivel de pobreza es posible debido a los siguientes factores:}

\section{Crecimiento económico sostenido traducido en un aumento del ingreso per cápita.}

Ingresos más altos y disminución en la desigualdad de los ingresos. Es decir, el aumento de los ingresos laborales en los hogares pobres fue el factor más determinante en la reducción de la pobreza. Las transferencias (tanto públicas como privadas) y el resto de los ingresos contribuyeron, pero en menor grado, a este descenso.

Hay algunos cambios en las tendencias: como el aumento de hogares con jefatura femenina, el incremento de los niveles educativos o la disminución del tamaño medio de los hogares y la tendencia hacia una menor concentración del ingreso.

Nadie tiene una fórmula mágica para provocar un rápido crecimiento en un país. Si existiera, no habría países pobres. Hoy, sin embargo, se comprende mejor el proceso de crecimiento a largo plazo, identificando los factores que lo determinan y las medidas que pueden utilizar los gobiernos para tratar de influir en ella. Las tasas a las que un país ahorra e invierte, es decir, la tasa a la que acumula bienes de capital, son junto con las variaciones de la productividad, importantes factores que determinan el nivel de vida que puede alcanzar su población.

\section{Pobreza y desigualdad en el ecuador: antecedentes de los años 90}

Es importante mencionar que históricamente el auge económico que trajo el banano y la industrialización por sustitución de importaciones en los 60, logrando la instalación de fábricas en busca del progreso, lo que hizo indispensable el surgimiento de la clase media, con personas que fueran profesionales, y más específicamente en la década del 70 con la explotación y exportación petrolera, la expansión del Sistema Financiero, el crecimiento de las Ciudades como Quito y Guayaquil.

La aparición de la primera generación de la clase media ecuatoriana se remonta a la década de los setenta, con el boom petrolero, y cobijada dentro de un régimen dictatorial. Esta clase con el paso 
del tiempo se fue desarrollando dentro de las ciudades, basado principalmente en actividades de carácter comercial y bancario. Por lo tanto, muchas familias pudieron ascender de clase gracias a la dinámica de la economía y también en parte a la educación provista por el Estado, y principalmente por la mano invisible que motiva a salir adelante individualmente. Cabe mencionar que su estilo de vida fue generalmente de tipo modesto, y así poco a poco se puede decir que fueron transformándose en una clase pujante que aspiraba llegar a manejar el país, ubicarse dentro del gobierno y mejorar en cierto modo el desarrollo económico dentro de su visión de desarrollo.

La región, y dentro de esta también el Ecuador, lograron en estas últimas décadas buenos niveles de crecimiento económico, estabilidad política, e inclusiones que permitieron el incremento y renacimiento de una amplia clase media ya casi olvidada, que se constituye en la columna económica y social, dentro de este marco democrático robustecido. La clase media que exige nuevas políticas a favor de una estabilidad macroeconómica perdurable, que los refuerce y mejore su bienestar.

Sin embargo, para hablar de pobreza tenemos que remontarnos a la gran crisis que afectó a la economía del Ecuador a finales de los noventa, expresada en el incremento de las tasas de desempleo en el país y los conflictos sociales por los programas de ajuste implementados que se reflejaron en el alto costo social en términos del incremento de las desigualdades económicas en el país (Martínez, 2008). Pese a la riqueza y diversidad de sus recursos naturales, el Ecuador todavía se ubica entre los países con mayor pobreza e inequidad social en Sudamérica.

Sus problemas estructurales se reflejan en la competitividad internacional, por ejemplo, a su débil formación de habilidades en lo referente al capital humano, la falta de capital monetario, un deficiente sistema educativo, la presencia de debilidad institucional, falta de creencia en los políticos, la falta de infraestructura vial, entre otros.

La crisis macroeconómica de los años 1998 y 1999 tuvo efectos devastadores y duraderos, en especial en las zonas rurales de la Costa afectadas por El Niño y en la clase media urbana. En el corto plazo, el menor costo de la canasta de consumo promedio que resultó de esta medida benefició más a los hogares no pobres que a los pobres: la canasta de consumo del primer segmento, compuesta en un $46 \%$ por bienes duraderos, disminuyó 19\%, mientras que para el 
segundo segmento (hogares pobres) disminuyó solamente 2\%. Así, aún están por verse los efectos de mediano plazo de la dolarización en el crecimiento, el consumo y la pobreza.

La tasa nacional de pobreza basada en el consumo era del 45\% en 2001, mientras en 1990 era del 40\%. Durante el mismo período, el número de personas que viven en la pobreza aumentó de 3,5 a 5,2 millones. Los aumentos de la pobreza no estaban distribuidos de manera uniforme en todo el territorio nacional. Fueron mayores en las zonas urbanas de la Costa y de la Sierra, donde la tasa de pobreza aumentó en más de $80 \%$ entre 1990 y 2001. En cambio, la pobreza se mantuvo constante en las zonas rurales de la Costa y se elevó en 15\% en las zonas rurales de la Sierra. En consecuencia, el número de pobres que viven en las zonas urbanas se elevó de 1,1 millones a 3,5 millones, de tal manera que, en 2001, el número de pobres urbanos superó al de los pobres rurales, lo que llevó a una urbanización de hecho de la pobreza. Al mismo tiempo, las tasas de pobreza continuaron siendo las más altas en las zonas rurales, donde viven los más pobres de los pobres.

Además de la brecha, el gasto social del sector público en el Ecuador ha sido, desde 1990, uno de los más bajos de los 19 países considerados en la estadística de la CEPAL (2007). También es de las pocas naciones de América Latina y el Caribe que muestra un porcentaje relativamente constante y hasta decreciente, a diferencia de las otras en que ha crecido especialmente en el último quinquenio.

\section{Gráfico 3. Gasto Público Social en porcentajes del PIB (1990-2004)}

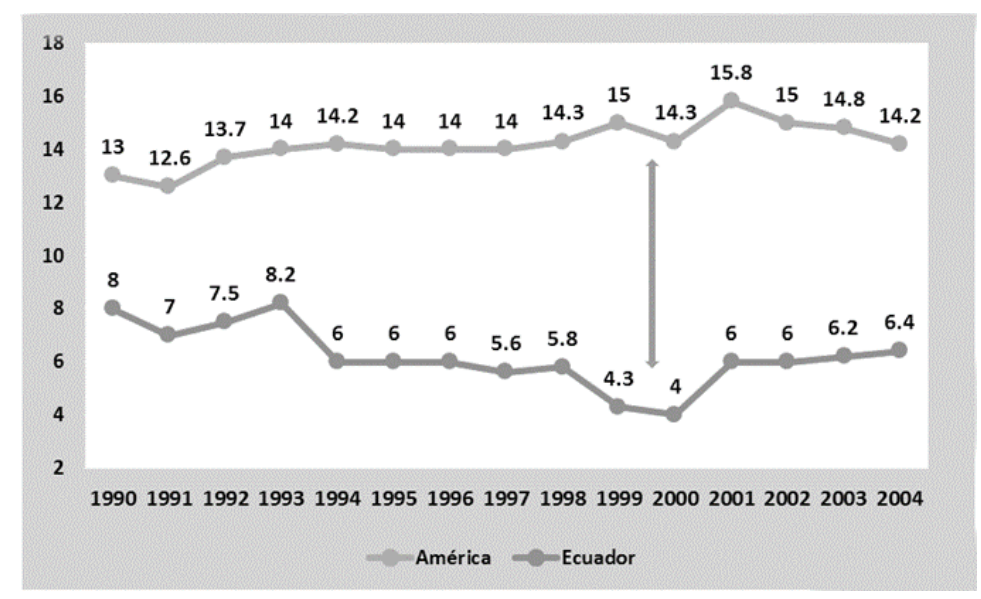

Fuente: CEPAL, Anuario Estadístico de América Latina y el Caribe 2007. Elaborado por: Autores 
Se puede observar que durante el periodo de crisis en el Ecuador la asignación del gasto de los gobiernos al sector social era mínima respecto a los demás países de América Latina. Esta crisis condujo al proceso de dolarización en Ecuador, y se esperaba que la estabilidad monetaria favoreciera la recuperación económica; pero los hechos demuestran no solamente que la economía no se ha estabilizado, sino que han aparecido nuevos desequilibrios tales como déficit fiscal y en la balanza de pagos, tipo de cambio sobrevaluado y el ajuste en el futuro posiblemente tomará una forma recesiva, ante la rigidez de los salarios y precios a la baja. Las perspectivas favorables en los albores de la dolarización no pudieron aprovecharse, porque la reconversión productiva demandaba crédito y el sistema financiero nacional no pudo responder.

\section{Gráfico 4. Evolución de la pobreza de consumo 1995-2006 (en porcentaje)}

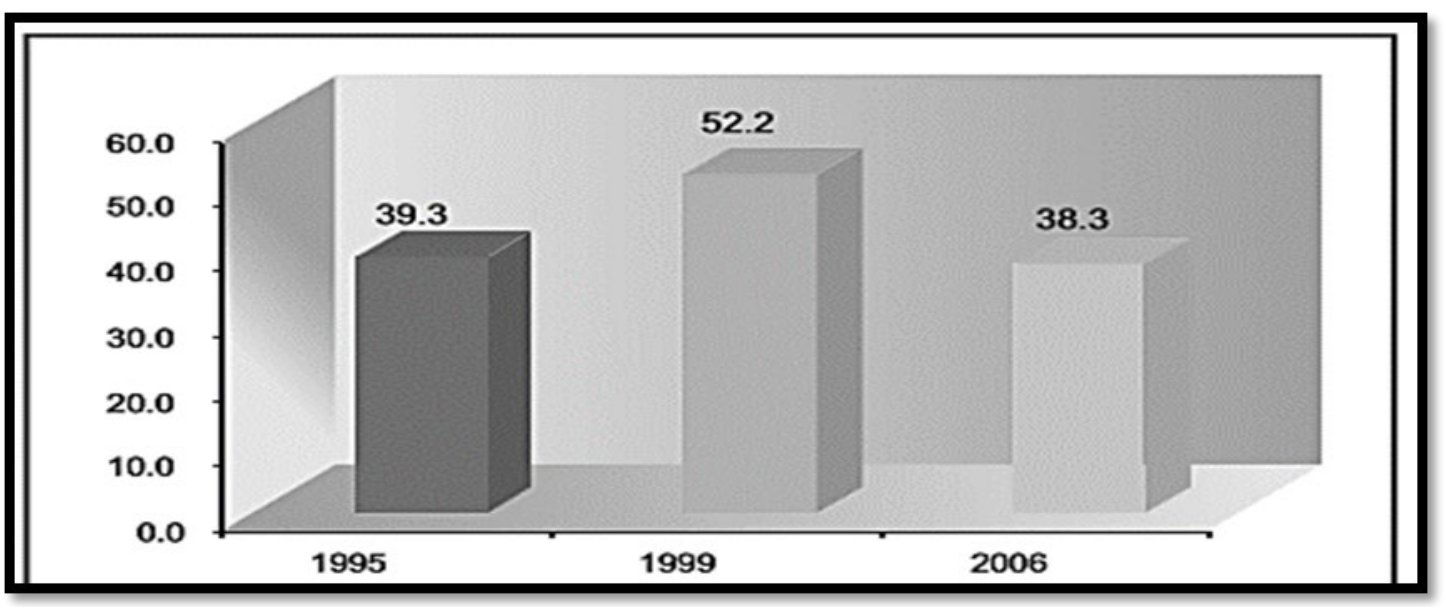

\section{Tomado de: Encuesta de Condiciones de Vida-INEC 1995, 1999 Y 2006.}

En 1995 el 39,3\% de la población ecuatoriana se ubicó por debajo de la línea de pobreza, mientras que, durante la crisis económica y financiera en 1999, este porcentaje ascendió a 52,2\%. No obstante, para el año 2006, siete años después, este valor se redujo en 13,9\% llegando a niveles similares a los presentados en 1995.

Para determinar si la tendencia de la pobreza es realmente decreciente o este comportamiento sólo se observa en el agregado de consumo, se presenta a continuación la incidencia de pobreza de ingresos para el área urbana calculada a partir de las Encuestas de Empleo y Desempleo (ver gráfico 5). 
A partir de 1999 la tendencia de la incidencia de la pobreza es decreciente y, a diferencia de la incidencia calculada a partir del agregado de consumo, los niveles observados para el año 2006 son inferiores a los del año 1995. También se observa que para 1999, el feriado bancario hizo que la pobreza por nivel de ingresos en el país sea relativamente alta, posteriormente, se estabilizó la economía con la adopción de la Dolarización se muestra que ha existido una disminución.

Desde el 2004 en adelante se observa que la dolarización permitió mantener estables los niveles de precios en la economía, y la capacidad de poder adquisitivo de las personas mejoró considerablemente, el desempeño de las políticas económicas a partir del 2007 fueron un mecanismo que contribuyó en la reducción de la pobreza en el país.

\section{Gráfico 5. Evolución de la pobreza de ingresos, área urbana 1995-2006}

\section{(En porcentaje)}

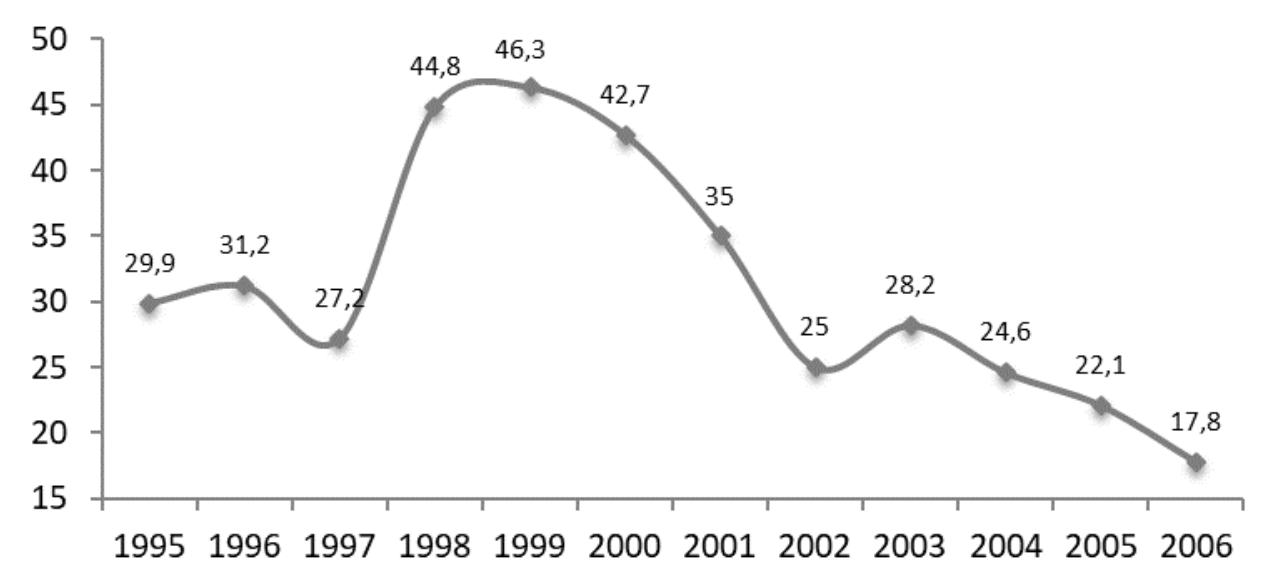

Fuente: ENEMDU -INEC, Encuestas de Empleo y Subempleo.

Elaboración: Autores

\section{Tendencias recientes de la pobreza en el ecuador}

El crecimiento en Ecuador ha sido inclusivo, con un efecto directo en la reducción de los niveles de pobreza y desigualdad, y el crecimiento de la clase media. Entre 2007 y diciembre de 2014, la pobreza medida por ingresos (usando la línea de pobreza nacional) disminuyó del 36,7\% al $22,5 \%$, mientras que la pobreza extrema se redujo desde el $16,5 \%$ hasta el $7,6 \%$. 
Gráfico 6. Porcentaje de Pobreza en el Ecuador

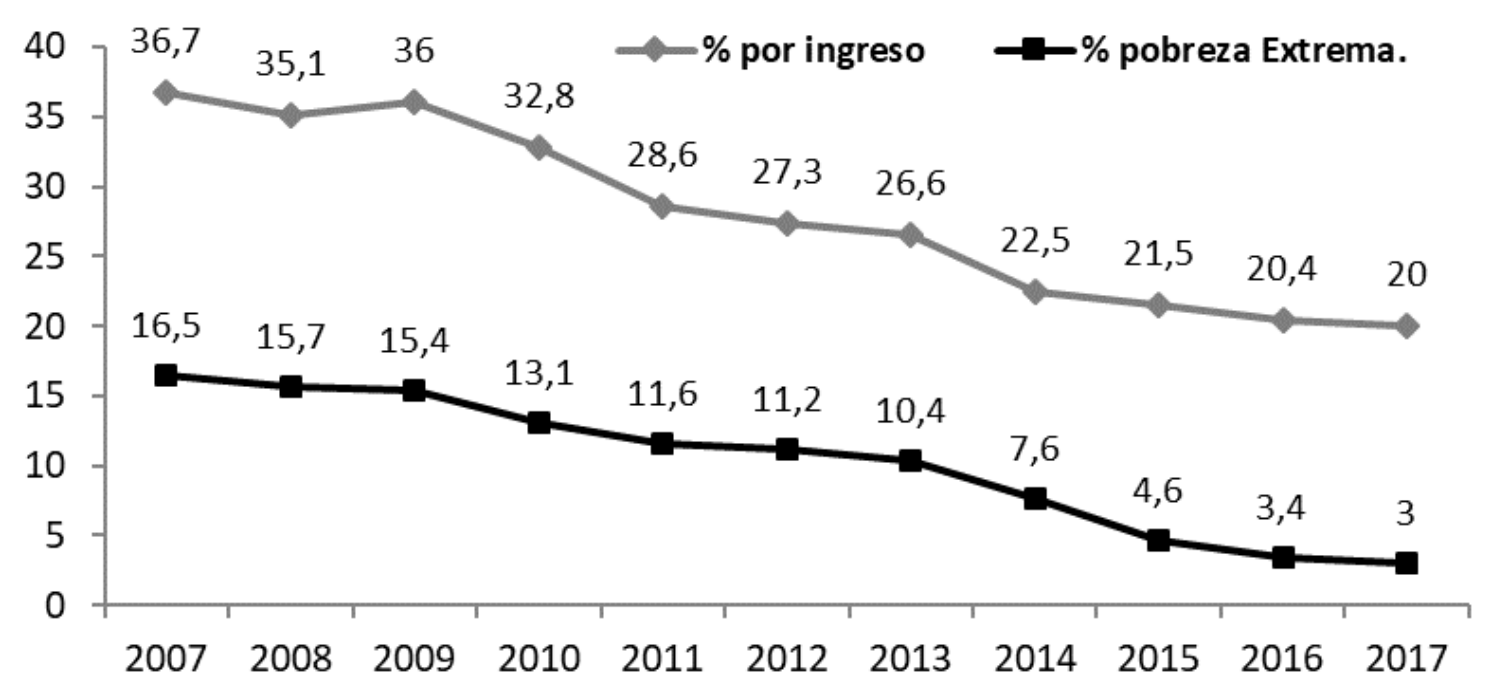

Fuente: ENEMDU-INEC, rondas de diciembre. Elaborado por: Secretaria Técnica para la

Erradicación de la pobreza-SENPLADES. Nota. A partir del 2015 son previsiones de pobreza.

Para el 2015 la SENPLADES espera que el gobierno pueda llegar a reducir la pobreza en el Ecuador hasta llegar a un 4,7\% los cambios esperados requerirán de una mayor coordinación de políticas sociales vinculadas a reducir la brecha de este indicador.

El gobierno muestra los avances de la reducción de la pobreza por ingreso y la pobreza extrema presentados a partir del Plan Nacional del Buen Vivir. En el año 2007 el porcentaje de pobreza era del $36,7 \%$, y la pobreza extrema del $16,5 \%$ durante los primeros 7 años la brecha ha presentado una disminución llegando al 2014 a 22,5\% la pobreza por ingreso y la pobreza extrema al 7,6\%, lo que se plantea en el nuevo plan es tratar llegar a la meta propuesta para el 2017 de $20 \%$ la pobreza por ingreso y apenas sea el 3\% la pobreza extrema en el país esto requiere de mayor trabajo por parte de los organismos encargados de la pobreza en el país. 
Tabla 1. Pobreza por Zona

\begin{tabular}{|c|l|r|r|r|}
\hline \multirow{7}{*}{ Indicador } & \multicolumn{1}{|c|}{ Área } & \multicolumn{1}{c|}{ dic-13 } & dic-14 & Diferencia \\
\hline \multirow{4}{*}{ Pobreza } & Nacional & $25,55 \%$ & $22,49 \%$ & $-3,06$ \\
\cline { 2 - 5 } & Urbano & $17,63 \%$ & $16,3 \%$ & $-1,2$ \\
\cline { 2 - 5 } & Rural & $42,03 \%$ & $35,29 \%$ & $-6,74$ \\
\hline \multirow{3}{*}{ Pobreza Extrema } & Nacional & $8,61 \%$ & $7,65 \%$ & $-0,96$ \\
\cline { 2 - 5 } & Urbano & $4,39 \%$ & $4,49 \%$ & 0,10 \\
\cline { 2 - 5 } & Rural & $17,39 \%$ & $14,33 \%$ & $-3,06$ \\
\hline
\end{tabular}

Fuente: ENEMDU-diciembre 2014.

Elaborado por: Autores

Gráfico 7. Comportamiento del Índice de Gini en el Ecuador (2007-2017)

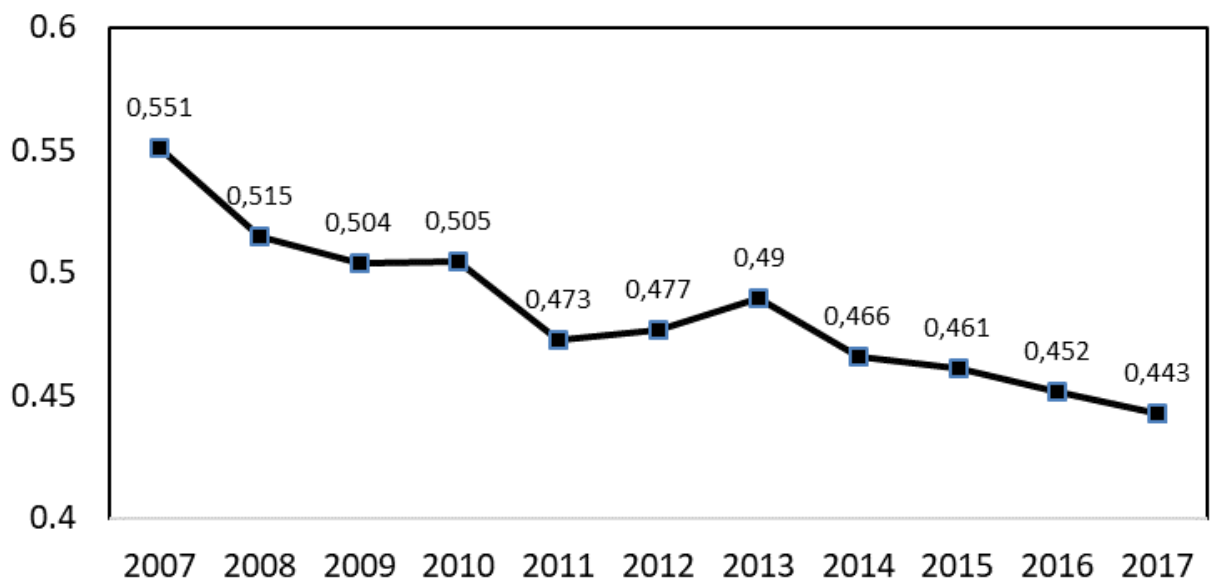

Fuente: Instituto Nacional de Estadística y Censos, INEC/ Encuesta Nacional de Empleo, Desempleo y Subempleo

Elaboración: Secretaría Nacional de Planificación y Desarrollo, SENPLADES. Nota: A partir del año 2015 son previsiones

Respecto a la pobreza extrema a nivel nacional, se observa una variación de 0,94 \% pasando de 8.61\% en diciembre 2013 a 7,65\% en diciembre 2014. En el área urbana la incidencia de pobreza extrema varió de 4,39\% en diciembre 2013 a 4,49\% en diciembre 2014. El área rural. 
la pobreza extrema se redujo $3,06 \%$ de $17.39 \%$ en diciembre de 2013 a 14,33\% en diciembre de 2014. Mientras a nivel global el sector social de la economía ecuatoriana ha presentado mejoras en estos últimos años debido al incremento del gasto público y su aporte al diseño de políticas con el fin de reducir la pobreza en el país.

Para el año 2007 el índice estuvo en 0,55 siendo relativamente alto, a partir del año 2008 se observa que el índice fue de 0,515 disminuyendo a 0,504 en el año 2009. En el siguiente año el índice era similar al año anterior por lo que no presentó mucha variación, los resultados esperados para el año 2011-2012 fueron favorables ya que este índice se ubicó en 0,473 y 0,48 respectivamente. Con respecto a diciembre de 2013 tanto a nivel nacional, urbano y rural existen disminuciones en el coeficiente de Gini, pero no son muy significativos.

Al año 2014, el coeficiente de Gini a nivel nacional fue de 0,4665, en el área urbana fue de 0,4580 y 0,4396 en el área rural. De manera general el crecimiento durante estos años a pesar de no ser muy significativo da indicios de alerta al cumplimiento del indicador, ya que el coeficiente de GINI es un indicador de carácter estructural y que para su reducción se requiere de grandes esfuerzos a nivel de gobierno.

Durante los 3 últimos años se muestra una tendencia constante donde los cambios son no estadísticamente significativos y se puede concluir que leves cambios anuales no permitirían alcanzar el cumplimiento de la meta al año 2017. A pesar de estos notables resultados, todavía persisten desafíos para la sostenibilidad tanto de los logros alcanzados en reducción de pobreza y desigualdad, como del crecimiento económico. Estos desafíos incluyen por un lado la reducción de la desigualdad y la pobreza, ya que, a pesar de la significativa disminución, los niveles de pobreza siguen siendo muy superiores en las áreas rurales. Por otro lado, un entorno internacional de progresiva.

\section{Asistencia Social y Programas de Lucha Contra la Pobreza}

Desde las primeras iniciativas, que comenzaron a mediados de los años noventa, el crecimiento de estos programas de asistencia social en los países latinoamericanos ha sido constante, tanto en términos de cobertura de la población como de gasto. No obstante, el panorama regional es heterogéneo. 
El presupuesto promedio en los países de América Latina equivale al $0,3 \%$ del PIB aproximadamente. El Ecuador, con su programa Bono de Desarrollo Humano, poseía el mayor presupuesto en relación con el PIB $(1,17 \%)$ al final de la década pasada, seguido por Oportunidades de México $(0,51 \%)$ y por el programa Asignaciones familiares de Uruguay $(0,45 \%)$. Por otro lado, existen programas más modestos tanto en cobertura como en financiamiento, como es el caso del programa Comunidades Solidarias Rurales en El Salvador, que se desarrolla solo en áreas rurales, o el programa Abrazos de Paraguay, que si bien tiene un alcance nacional, beneficia únicamente a una pequeña población.

En promedio, la cobertura expresada como porcentaje de personas que pertenecen a los hogares beneficiarios ronda el $13 \%$ de la población de los países, lo que depende tanto de la envergadura de programas como de la proporción de población pobre o vulnerable y que además cumple los criterios de elegibilidad definidos por cada programa. En el siguiente cuadro se muestran algunos programas incentivados por los gobiernos de los distintos países de la región (ver tabla 2).

En la región existen notables diferencias de un país a otro, no sólo en cuanto a la cantidad de recursos que efectivamente pueden movilizar hacia los sectores sociales, sino también respecto del esfuerzo macroeconómico que representa el presupuesto público social.

Naturalmente, la capacidad de dar mayor prioridad macroeconómica al gasto social depende de un sin número de variables económicas, "políticas" y sociales. Una de las variables determinantes son los ingresos fiscales, que imponen un cierto límite al presupuesto total. No obstante, el alza a nivel regional del gasto como porcentaje del PIB, del $13,8 \%$ en $1990-1991$ al $19,1 \%$ en $2012-$ 2013, se registra una gran heterogeneidad, tanto de los niveles iniciales de gasto social en porcentajes del PIB como de los niveles actuales.

Tabla 2. Programas de Transferencia condicionadas 2009

\begin{tabular}{|l|l|c|c|}
\cline { 3 - 4 } \multicolumn{1}{c|}{} & \multicolumn{2}{c|}{ Población Cubierta } \\
\hline \multirow{2}{*}{ País } & \multicolumn{1}{c|}{ Programa } & $\begin{array}{c}\text { Del Total de } \\
\text { a Población }\end{array}$ & $\begin{array}{c}\text { Del Total } \\
\text { población pobre }\end{array}$ \\
\hline Argentina & Asignación universal por Hijo & $8,3 \%$ & $46,4 \%$ \\
\hline Argentina & Programa de Ciudadanía Porteña & $9,6 \%$ & $100 \%$ \\
\hline Bolivia & Bono Juancito Pinto & $17,5 \%$ & $32,4 \%$ \\
\hline
\end{tabular}




\begin{tabular}{|c|c|c|c|}
\hline Bolivia & Bono Madre Niño-Niña & $3,5 \%$ & $6,4 \%$ \\
\hline Brasil & Bolsa Familiar & $26,4 \%$ & $84,6 \%$ \\
\hline Chile & Chile Solidario & $6,8 \%$ & $51,7 \%$ \\
\hline Colombia & Familias en Acción & $25,2 \%$ & $56,5 \%$ \\
\hline Costa Rica & Avancemos & $3,3 \%$ & $17,4 \%$ \\
\hline Ecuador & Bono de Desarrollo Humano & $44,3 \%$ & $100 \%$ \\
\hline El Salvador & Comunidades Solidarias Rurales & $8,2 \%$ & $17,1 \%$ \\
\hline Guatemala & Mi Familia Progresa & $22,6 \%$ & $39,7 \%$ \\
\hline Honduras & Programa de asignación familiar & $8,7 \%$ & $12,3 \%$ \\
\hline México & Oportunidades(ex progresa) & $24,6 \%$ & $62,8 \%$ \\
\hline Panamá & Red de oportunidades & $10,9 \%$ & $39,5 \%$ \\
\hline Paraguay & Tekoporá & $8,6 \%$ & $13,9 \%$ \\
\hline Perú & Juntos & $7,6 \%$ & $21,2 \%$ \\
\hline Rep. Dominicana & Solidaridad & $21,2 \%$ & $46,3 \%$ \\
\hline Uruguay & Asignaciones Familiares & $11,6 \%$ & $84,6 \%$ \\
\hline \multicolumn{2}{|c|}{ América Latina Promedio } & $14,94 \%$ & $46,27 \%$ \\
\hline
\end{tabular}

Fuente: Comisión Económica para América Latina y el Caribe (CEPAL), estimaciones sobre la base de los programas de protección social. Elaborado por: Autores.

En 1990-1991 (o el período más cercano con datos disponibles), países como el Ecuador, El Salvador, Honduras, México, Nicaragua y Trinidad y Tobago destinaron menos del 7\% del PIB a los sectores sociales; por el contrario, la Argentina, Costa Rica, Cuba, el Uruguay y Venezuela (República Bolivariana de) destinaron a esos sectores un 15\% o más, dichos resultados se observan en el gráfico 8. 
Gráfico 8. Evolución del Gasto Público Social, 1990-1991; 2012-2013 para América Latina y el Caribe en porcentajes del PIB

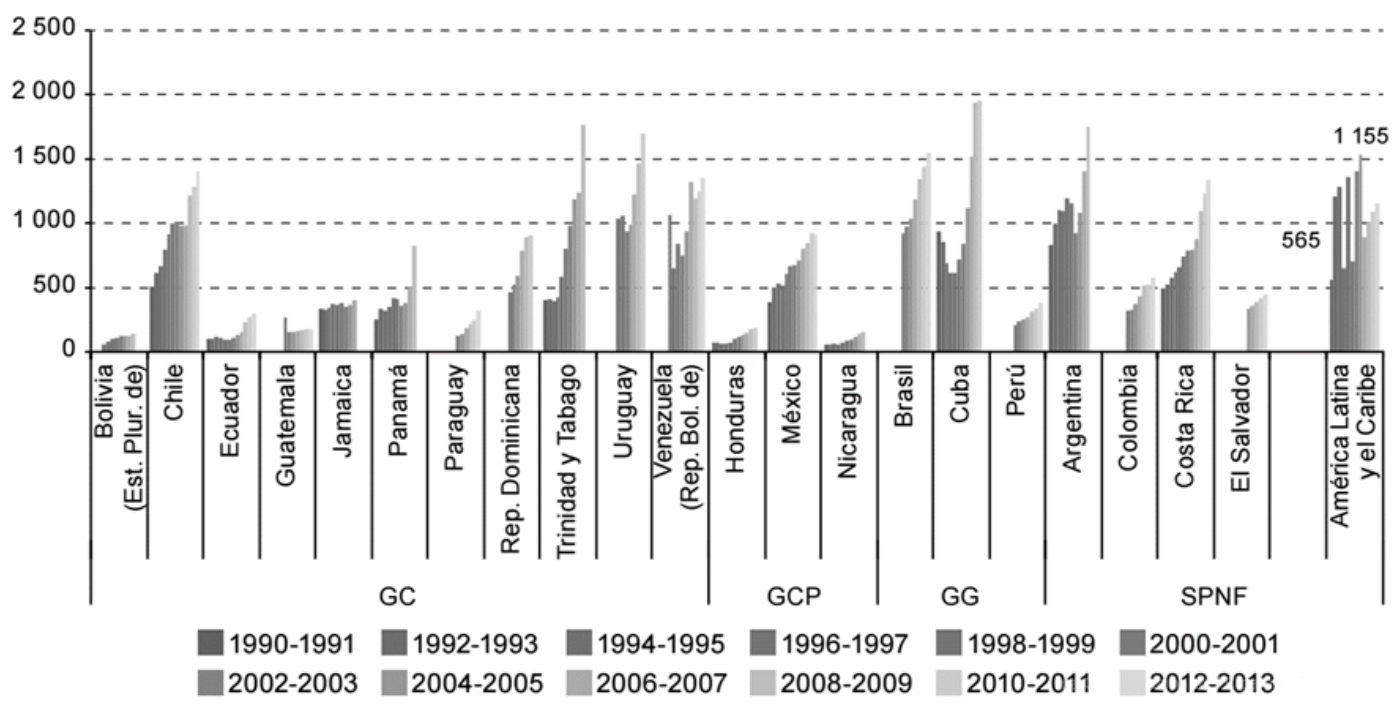

Tomado de: Comisión Económica para América Latina y el Caribe (CEPAL), Panorama

Social de América Latina, pág. 267, 2014.

Inversión Pública en el Ecuador

La Inversión pública en el Ecuador ha sido un factor importante para el desarrollo de sectores productivos y para erradicar la pobreza en el país. Un elemento importante que cabe destacar es la gran inversión que está haciendo el Gobierno en escuelas del milenio y en centros de salud, que esencialmente son hospitales básicos, que en unos casos se están repotenciando y en otros son nuevos. También están los centros infantiles del Buen Vivir (ver gráfico 9).

Gráfico 9. Crecimiento de la Inversión Pública en el Ecuador Millones de dólares (2008-2014)

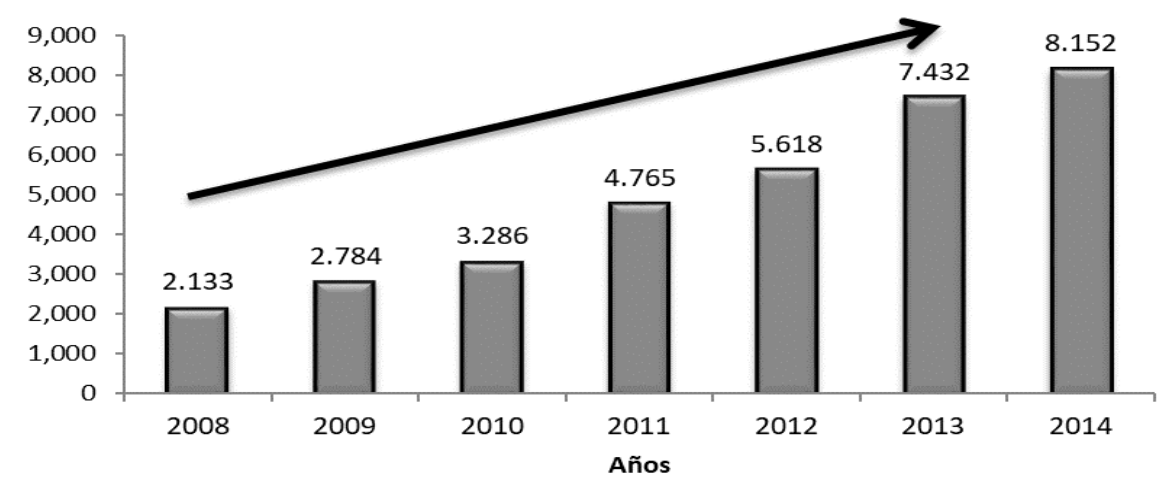

Fuente: Secretaria Nacional de Planificación y Desarrollo-SENPLADES.

Elaborado por: Autores. 
A partir del gobierno de la revolución ciudadana el incentivo de la inversión en la economía se ve reflejado a partir del 2008 donde la inversión fue de \$2.133 millones, el crecimiento de esta variable ha aumentado debido al crecimiento del PIB en la economía y a las políticas de redistribución del ingreso en el país llegando al 2014 a $\$ 8.152$ millones una cifra importante para reducir los niveles de pobreza y desempleo (ver gráfico 10).

\section{Gráfico 10. Inversión Social como porcentaje del PIB en el Ecuador 2007-2014}

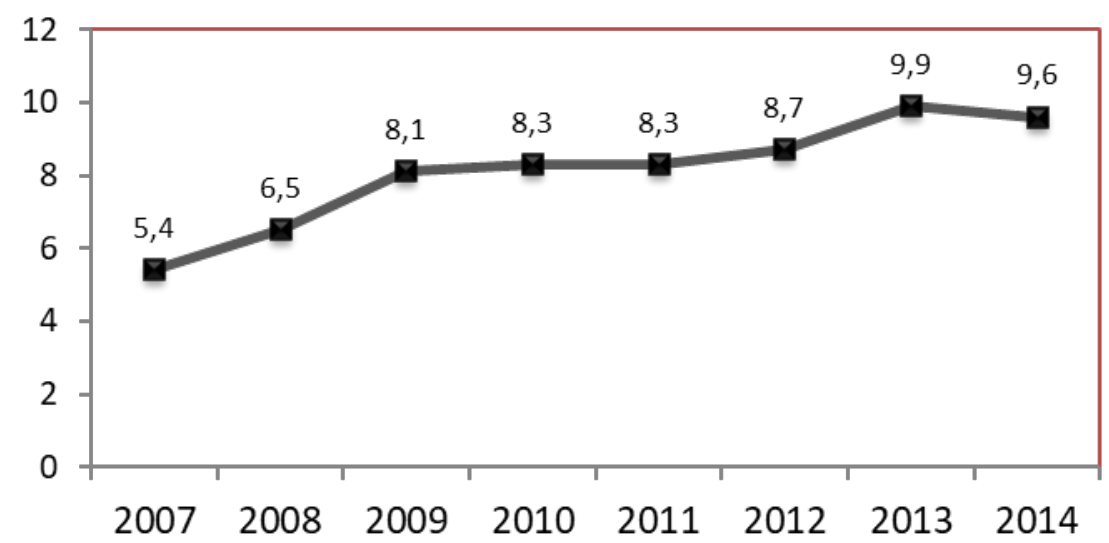

Fuente: Sistema Integrado de Gestión Financiera-Ministerio de Finanzas. Elaborado por: Autores.

SENPLADES argumenta que para el año 2015 se espera invertir $\$ 8,000$ millones donde $\$ 1.200$ millones serían para el sector social que representa el aproximadamente el 15\% del PIB, por lo que se observa que la cifra será menor para este año debido a factores externos como la tendencia de la baja de los precios del petróleo que es una fuente importante de ingresos para el país esto nos harán recortar gastos para los diferentes destinos de inversión en el país.

La inversión en el sector social en el país presenta un incremento respecto a la asignación en el 2007 la inversión fue de 5,4\% respecto al PIB. La inversión económica en los sectores de salud, educación, deporte, vivienda, e inclusión económica y social, se incrementó 4,2 veces respecto a 2007 llegando en el 2014 al 9,6\% respecto al PIB. Los avances en los sectores ya mencionados, han sido un factor fundamental para los logros alcanzados por el actual gobierno planteados en el objetivo 2 del Plan Nacional del Buen Vivir para reducir la pobreza los esfuerzos han dado buenos resultados. 


\section{Gráfico 11. PRIORIDADES DE INVERSIÓN 2015}

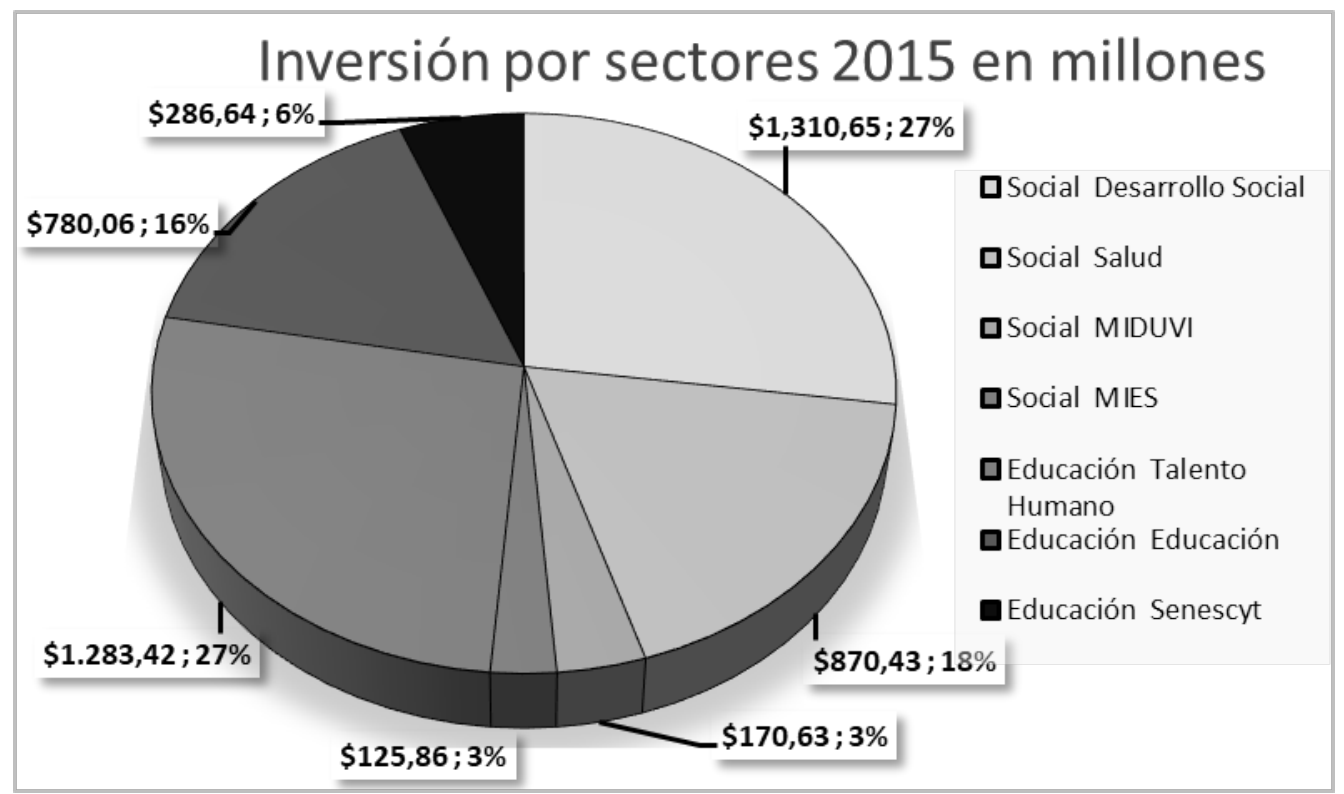

Fuente: Ministerio de Finanzas -Proforma del PGE-2015.

Elaborado por: Autores.

\section{DESARROLLO SOCIAL US\$ 1.310,65 millones}

SALUD US\$ 870,43 millones destinados al Fortalecimiento del modelo de atención integral en Salud, Prevención y promoción y provisión y Prestación de Servicios de Salud, Vigilancia y control del Sistema Nacional de Salud.

MIDUVI US\$ 170,63 millones destinados a Vivienda y reasentamientos: Vivienda rural y urbana, Socio vivienda. Intervención territorial integral. Generación de áreas verdes y espacios recreativos públicos.

MIES US\$ 125,86 millones para el Desarrollo Infantil: Construcción y equipamiento de CIBV Sistema de protección especial en el ciclo de vida. Protección social a la familia aseguramiento no contributivo inclusión económica y movilidad social.

TALENTO HUMANO US\$ 1.283,42 millones

EDUCACIÓN US\$ 780,06 millones Infraestructura Educativa. Calidad Educativa: Educación intercultural, Sistema Integral de Tecnologías Escuela y la comunidad, SIPROFE. Educación Inicial y Educación para Adultos. 
SENESCYT US\$ 286,64 millones dedicados el fortalecimiento de las capacidades y habilidades del Talento Humano. Calidad y democratización en el Sistema de Educación Superior. Investigación, desarrollo, innovación y/o transferencia tecnológica.

El salario básico unificado como principal variable para reducir las brechas con el costo de la canasta básica familiar en el Ecuador ha sido una medida para tratar de reducir la pobreza por ingresos en el país. En el gráfico 12 se observa la tendencia de crecimiento a partir del 2007 que fue de \$107 llegando a ser fijado en la actualidad a \$354. Este incentivo seguido de la afiliación a los trabajadores al IEES y el incremento del Bono de Desarrollo Humano en las familias trata de reducir la brecha de pobreza extrema en el país.

\section{Gráfico 12. Comportamiento del Salario Básico Unificado en el Ecuador} 2007-2015

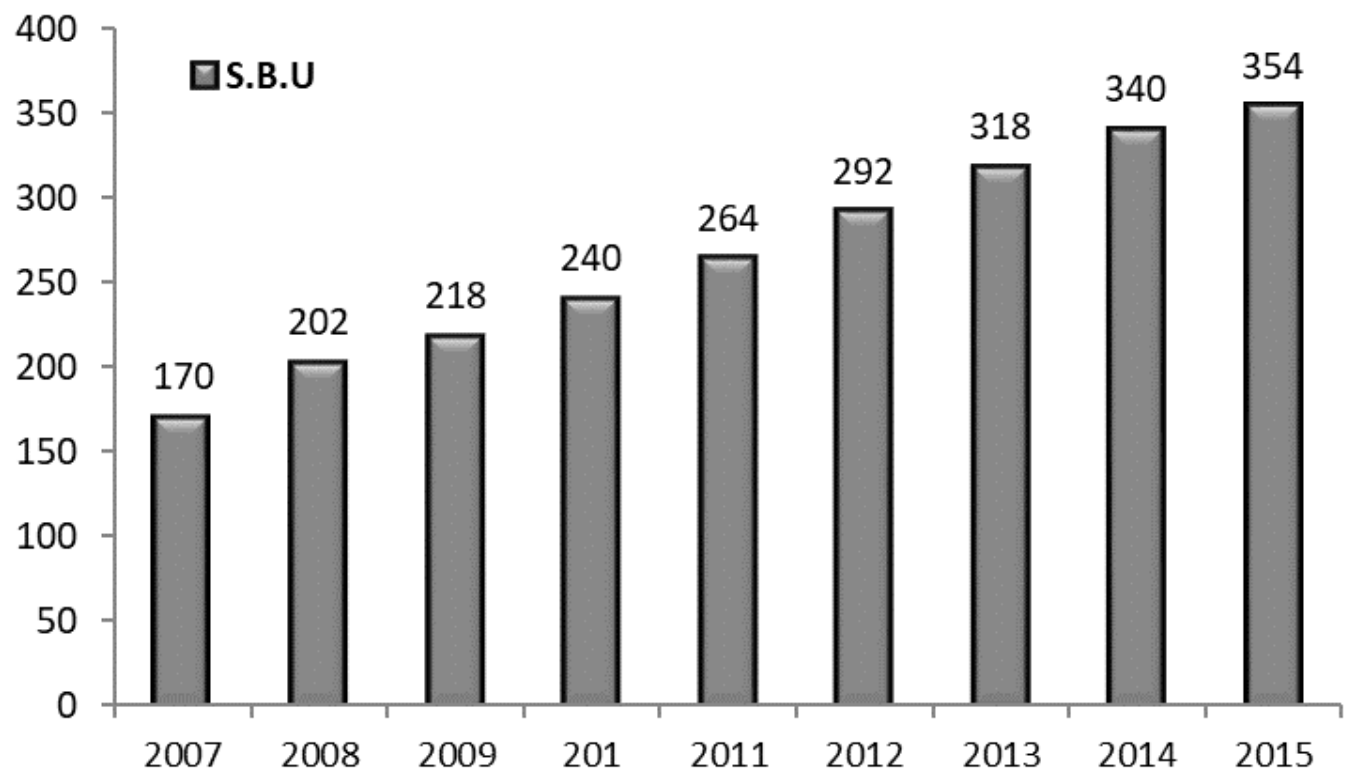

Fuente: Instituto de estadísticas y Censo-Sise.

Elaborado por: Autores. 


\section{Gráfico 13. Comportamiento de la Canasta Básica Nacional}

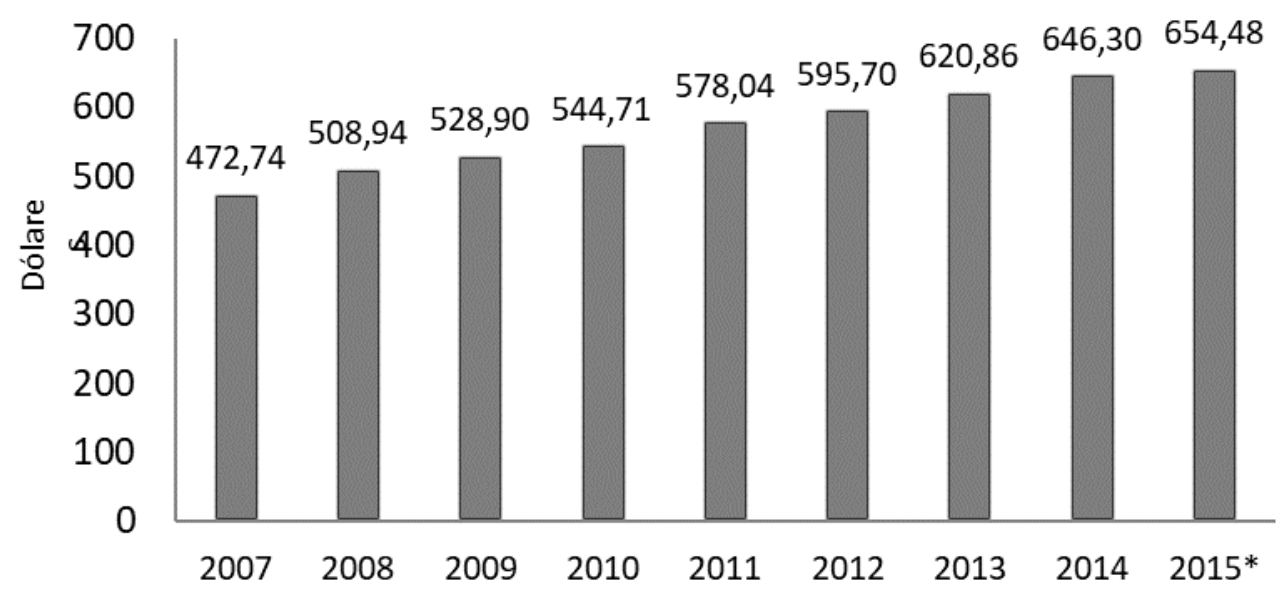

\section{Fuente: INEC Serie Histórica de la Canasta Básica Nacional febrero 2015. *La cifra prevista de marzo del 2015 en el Ecuador}

\section{Elaborado por: Autores}

En resumen, es claro que la pobreza no se puede eliminar por decreto, simplemente aumentando el salario, la vía para eliminar la pobreza es generar mayor riqueza, es decir crecimiento del PIB no petrolero para aumentar el pleno empleo, esta última es la fuente más importante para la reducción de la pobreza.

El incremento de la Canasta Básica en el Ecuador ha estado influenciado por el comportamiento de la inflación en el mercado. El poder adquisitivo de la población ha incrementado la brecha entre el salario y el costo de la canasta básica hasta el presente año cubre el 100\%. Cabe destacar la buena gestión del gobierno ya que en gobiernos anteriores no se trataba de beneficiar el esfuerzo de los trabajadores y el acceso de los bienes de consumo necesarios para satisfacer las necesidades básicas familiares era demasiado alto.

Sin embargo, el salario básico no es la meta para el régimen, pero sí es "el menor de los males" porque su monto evita los despidos y mantiene la competitividad del país. Partiendo de este criterio desde hace dos años existe el concepto de "Salario digno" que resulta de dividir los perceptores de sueldo por familia y el promedio de la Canasta Básica Familiar.

\section{Bono de Desarrollo Humano en el Ecuador}

El Bono de Desarrollo Humano ha pasado de ser solo un beneficio relacionado con la pobreza a una manera de insertar a los beneficiarios en el sector laboral, de salud y educativo. Con el 
objetivo a largo plazo de generar nuevas oportunidades en la población, se espera con el tiempo abandonar el programa.

El Bono de Desarrollo Humano: saltó de la pobreza a la inclusión social en el país ya que desde 2007 supone un ingente gasto público y cuyo producto más mimado es el Bono de Desarrollo Humano, el cual ha aumentado tres veces, de los 15 a los 50 dólares en el 2014, y beneficia ya a casi 2 millones de ecuatorianos en situaciones de penuria. Nuevos equipamientos educativos, sanitarios y de transporte han alcanzado numerosos puntos de la geografía nacional hasta ahora huérfanos de la implicación del Estado.

Indudablemente el Bono de Desarrollo Humano (BDH) y los programas de asistencia social del régimen cumplen un rol importante en la lucha contra la pobreza y la menor desigualdad del ingreso, porque sirven para aliviar la pobreza al aumentar el ingreso de familias pobres. En educación, se incrementa la tasa de escolaridad y asistencia al colegio, para mejorar el estado de salud de niños y población en extrema pobreza, y el acceso a los servicios de salud, además de incentivar la periodicidad de visitas médicas y vacunación.

Pero, se puede decir de la existencia de dos caminos que se pueden tomar para completar el avance hacia un mayor nivel de equidad con respecto a la distribución de la riqueza. Estas también se pueden combinar de diversas maneras. El lado fiscal, donde la herramienta son los impuestos a los sectores con los mayores ingresos y el otorgamiento de beneficios a los sectores más desfavorecidos de la sociedad. Además, podemos decir que las políticas sociales son el vínculo común para la asistencia de los pobres en la sociedad capitalista de visión occidental.

Otro sendero hacia la igualdad es el que privilegia una propuesta de cambio estructural, buscando una matriz productiva que internamente logre la generación de empleo de calidad que tan necesariamente necesita nuestra economía, que termine con una alta productividad, y una apropiación del capital humano ecuatoriano.

Cuando en una economía se presenta una estructura productiva de carácter polarizada, no encontramos que los mecanismos de las políticas públicas que buscan redistribuir la riqueza no van a solucionar nuestros problemas. Las políticas deben enfocarse a la generación de empleo, y más que eso que este empleo sea de calidad, tanto es así que en Ecuador cerca de $50 \%$ o más esta subempleado, dentro de esa categoría están los informales. O el caso de España que aunque se dice que está saliendo de su crisis, al generar más empleo, este empleo se ha caracterizado de 
mala calidad, contratos por horas, menores remuneraciones, o trabajos ocasionales que no permiten a la clase obrera trabajadora estabilizarse y especializarse.

La CEPAL en su informe de cambio estructural para la desigualdad (2014) menciona que la necesidad de incentivar la inversión de largo plazo, la diversificación de la estructura productiva $y$, muy especialmente, la mayor convergencia en niveles de productividad del conjunto de la economía. Dice que esta convergencia progresiva en el ámbito productivo y del empleo proveerá el sentido de pertenencia para el fortalecimiento de la ciudadanía, generará mayor predisposición al consenso de mejoras en el bienestar y, a la vez, promoverá las relaciones más virtuosas entre la participación de la sociedad y la orientación de la economía.

\section{Conclusiones}

Como se ha demostrado en el presente trabajo, la situación de pobreza que aqueja a gran parte de la población de los países latinoamericanos, y en el Ecuador sigue siendo el principal obstáculo a vencer en aras del beneficio de la sociedad. Las cifras revelan datos interesantes, si bien durante los últimos años se han logrado avances en el combate a la pobreza, esta no es aún una tarea resuelta. La coyuntura favorable de los elevados precios del petróleo durante los últimos tres años permitió la expansión del gasto público, en particular del gasto público social, como motor corrector de las desigualdades a través de los programas de transferencias condicionadas y la dotación de servicios de salud y educación gratuitos. Sin embargo, es necesario replantearse el modelo extractivista y dependiente del sector externo orientándolo a un cambio real de la matriz productiva, sentando las bases de una economía que converja en cuanto a productividad, reduciendo de esta manera las brechas de la desigualdad y el combate a la pobreza.

\section{Referencias Bibliográficas}

CEPAL (2014). Panorama Social de América Latina, Santiago de Chile.

CEPAL (2012a). Cambio estructural para la igualdad: Una visión integrada del desarrollo, Santiago de Chile.

CEPAL (2012b). Eslabones de la desigualdad: Heterogeneidad Estructural, empleo y protección social, Santiago de Chile.

CEPAL (2007). Anuario Estadístico de América Latina y el Caribe, Santiago de Chile.

INEC (2014). Encuesta Nacional de Empleo, desempleo y subempleo.

INEC (2006). Encuesta Nacional de Empleo, desempleo y subempleo. 
INEC (2006). Encuesta de Condiciones de Vida.

Martínez, M. (2008). Política Monetaria en el Ecuador: manejo y perspectivas, Fondo

Latinoamericano de reservas, Dirección de estudios económicos, No. 87, 2008, pp. 173-188.

Ministerio de Finanzas (2014). Proforma del Presupuesto General del Estado 2015.

OXFAM (2014). Iguales: Acabemos con la desigualdad extrema. Es hora de cambiar las reglas. 